\title{
STRUCTURAL, THERMOPHYSICAL AND MECHANICAL CHARACTERISTICS OF METAL FELT WICKS OF MODERN HEAT PIPES
}

\author{
Gershuni A., Zaripov V. \\ National Technical University of Ukraine “Kyiv Polytechnic Institute”, Heat Pipe Lab \\ 37 Prospect Peremogy, Kiev 03056, Ukraine \\ Phone: (+38)-044-4069526, Fax: (+38)-044-4069526 \\ E-mail: rial@ukrpost.ua, zaripoff@ukr.net \\ Baturkin V. \\ National Technical University of Ukraine "Kyiv Polytechnic Institute”/Institute of Space \\ Systems, Bremen, Germany \\ Robert-Hooke-Str. 7, 28359 Bremen, Germany \\ Phone: (+49)-421-244201610, Fax: (+49)-0421-244201120 \\ E-mail: baturkinvm@mail.ru
}

\begin{abstract}
The article reflects the results of many years' (since 1972) research of structural, hydrodynamic, thermophysical and mechanical properties of metal felt capillary structures (MFCS) of heat pipes (HP). These structures were made from the discrete copper, stainless steel, or nickel sintered fibres of 0.002 to $0.01-\mathrm{m}$ length and diameter within 20 to $70 \mu \mathrm{m}$. They were intended for the HP with shells of a copper, stainless steel, nickel, titan, nickel silver, and ceramics and filled with such heat carriers as nitrogen, ammonia, water, ethanol, methanol, acetone, sodium, etc. The HP worked in the range of temperatures from cryogenic level $\left(-190{ }^{\circ} \mathrm{C}\right)$ to high temperatures $\left(+800{ }^{\circ} \mathrm{C}\right)$. Analytical and experimental research is executed by the authors from National Technical University of Ukraine "Kyiv Polytechnic Institute” (Kyiv, Ukraine) supervised by Dr., Prof. M. Semena. On the basis of the conducted research the functional dependences are obtained for implementation into engineering calculations of heat-transfer characteristics of HP. The proposed design of rational HP with MFCS and elaborated technology of their fabrication made it possible to create and implement a variety of the heat pipes and systems on their basis for different fields of application.
\end{abstract}

KEY WORDS: heat pipe, metal fibre, capillary structure

\section{NOMENCLATURE}

$R_{h p} \quad$ heat-pipe thermal resistance (K/W)

$\lambda_{\text {eff }}$ heat conductivity of capillary structure saturated with liquid $(\mathrm{W} /(\mathrm{m} \cdot \mathrm{K})$

$\lambda_{s} / \lambda_{1}$ ratio of fibre material heat conductivity and liquid conductivity (-)

$\varepsilon_{\max }$ maximal obtainable porosity of capillary structure (-)

$Q_{\max }$ maximal heat transfer of heat pipe (W)

$l_{f} \quad$ length of fibre (mm, m)

$d_{f}$ diameter of fibre $(\mu \mathrm{m}, \mathrm{m})$ 
$\Theta \quad$ limiting angle of wetting (grad)

$\Delta V / V$ ratio of volume of pores to total volume of capillary structure

$D$ pore diameter $(\mu \mathrm{m}, \mathrm{m})$

$\Delta P_{\text {cap }}$ capillary pressure $\left(\mathrm{N} / \mathrm{m}^{2}\right)$

$K \quad$ liquid permeability of capillary structure saturated with liquid $\left(\mathrm{m}^{2}, \mu \mathrm{m}^{2}\right)$

\section{INTRODUCTION}

Application of MFCS as capillary structures (CS) of HP enables the creation of such designs of HP, which are often unrealizable on the basis of other types of CS (made from metallic screens, powders, grooves, etc.). It is especially important in setting some specific requirements to HP: operation in the gravity-opposite direction, application of CS on irregularly shaped surfaces or reconfiguration of fabricated HP, etc.

Advantages of CS made from discrete metal fibres over the other types of CS are conditioned by a number of their unique properties: very wide range of effective porosity (from 0.5 or less, if necessary, to 0.96 or higher); wide range of pore diameters (from $5 \mu \mathrm{m}$ or less to $300 \mu \mathrm{m}$ or more), and absence of closed pores (Fig. 1). It results in the optimum combination of basic hydraulic characteristics of MFCS, namely, high coefficient of permeability and available capillary head.

Optimum hydraulic characteristics of MFCS in combination with their high enough frame heat conductivity (from 0.5 to $50 \mathrm{~W} /(\mathrm{m} \cdot \mathrm{K})$ ) provide high-efficient heat engineering characteristics of HP: low thermal resistance $R_{h p}$ and high maximal heat transfer $Q_{\max }$.
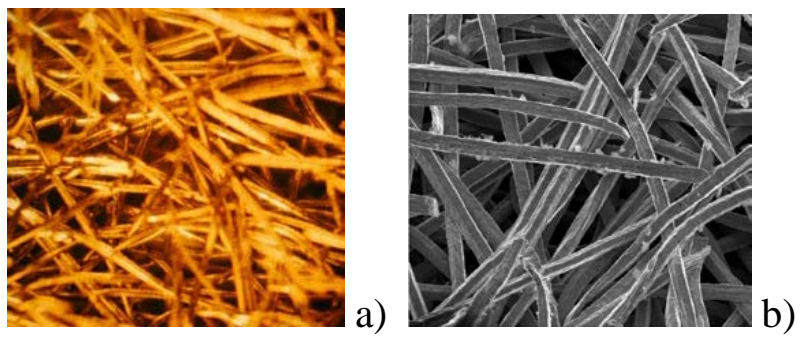

Fig.1. Appearance of metal felt capillary structures (75-fold magnification): fibres (a) from copper by diameter of $20 \mu \mathrm{m}$ and (b) from stainless steel, $30 \mu \mathrm{m}$.

For example, for low-temperature HP the values of $R_{h p}$ are, as a rule, within the range of 0.03 to $0.3 \mathrm{~K} / \mathrm{W}$, and the value of $Q_{\max }$ reaches dozens of watts during operation against gravity and hundreds of watts in absence of its influence. It is possible to find in-depth information on characteristics of HP with MFCS and the results of their practical application in (Semena et al., 1984) and additional information on the properties of metal felt materials in (Kostornov, 2002). 


\section{STUDY OF STRUCTURAL CHARACTERISTICS OF MFCS}

Among initial structural characteristics of MFCS the following are: diameter $d_{f}$ and length $l_{f}$ of fibre, average porosity $\varepsilon$, maximal $D_{\max }$, middle (effective) $D_{\text {mid }}$ and minimal $D_{\min }$ diameters of pores, and also pore size distribution.

Usually for HP application the discrete fibres of a diameter from 20 to $50 \mu \mathrm{m}$ are used, and lately, ultrafine fibres from 4 to $18 \mu \mathrm{m}$. The length of separate fibre is from 0.001 to $0.003 \mathrm{~m}$ and longer, if necessary. Average volume porosity of CS is within the range from 0.6 to 0.96, and by using micro fibres extremely high porosities from 0.98 to 0.995 (Adkins et al., 1994) could be attained. Obtainable (maximal) porosity of MFCS can be defined by the following empiric dependence:

$$
\varepsilon_{\text {max }}=\exp \left(-6 d_{f} / l_{f}\right)
$$

The MFCSs are nonuniform structures. Therefore, they are characterized by the differential or integral (cumulative) pore size distribution (Fig. 2).

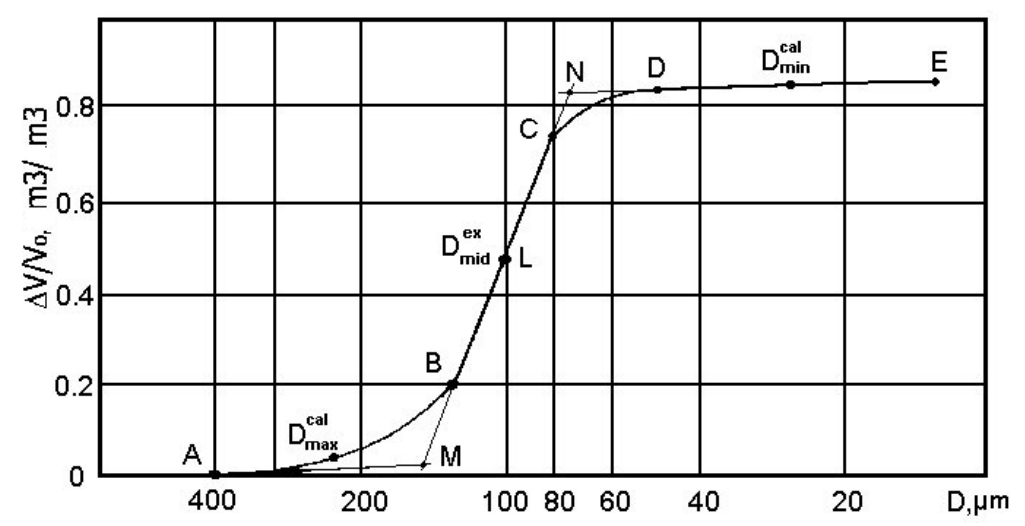

Fig. 2. Curve of cumulative distribution of relative volume of pores versus pore diameter. Volume porosity $\varepsilon=0.85, d_{f}=30 \mu \mathrm{m}, l_{f}=0.003 \mathrm{~m}$

Such distributions can be obtained by mercury intrusion porometry. From cumulative distribution curves it is possible to extract information about the maximal, middle and minimum sizes of pores (Fig. 2). Typical ranges of sizes of MFCS pores are: $D_{\max }=50$ to $300 \mu \mathrm{m} ; D_{\text {mid }}=20$ to $150 \mu \mathrm{m} ; D_{\min }=5$ to $50 \mu \mathrm{m}$.

More correct values of the sizes of MFCS pores (especially, high-porous) are obtained by other methods of their determination such as: method of gas permeability in combination with the model of ideal porous medium and method of extruding of liquid from pores (method of Barus-Bechgold).

In processing the experimental data by the indicated methods, the authors obtained the following dependences for calculations of MFCS parameters:

$$
\begin{aligned}
& D_{\max }=d_{f}^{0.7} l_{f}^{0.3} \varepsilon^{2}(1-\varepsilon)^{-0.5} ; \\
& D_{\text {mid }}=0.4 d_{f}^{0.7} l_{f}^{0.3} \varepsilon^{1.6}(1-\varepsilon)^{-0.5} ; \\
& D_{\min }=0.1 d_{f}^{0.7} l_{f}^{0.3} \varepsilon(1-\varepsilon)^{-0.5} .
\end{aligned}
$$




\section{HYDRODYNAMIC CHARACTERISTICS OF MFCS}

The considered structural characteristics of MFCS determine capillary-transport properties are: capillary pressure $\Delta P_{\text {cap }}$, coefficients of liquid permeability $K_{1}$ and $K_{2}$ (permeability at liquid movement in two orthogonal directions), limiting wetting angle, characteristics of capillary absorption of heat carrier into dry structure. Hydrodynamic characteristics of MFCS were investigated using the samples from copper and stainless steel fibres with diameters of $20,30,40,55$, and $70 \mu \mathrm{m}$ with porosities from 0.58 to 0.96 , and length of $3 \mathrm{~mm}$, with water, acetone, ethanol, and benzyl alcohol as working fluids. As a result of experimental data processing and modelling the authors have obtained the following dependences:

- for determination of capillary pressure:

$$
\Delta P_{\text {cap }}=35 \sigma \cos \theta(1-\varepsilon) d_{f}^{-1} \sqrt{1-\varepsilon_{\max }},
$$

- for determination of permeability across the axis of fibres (across the plane of felting):

$$
K_{1}=\frac{d_{f}^{2}}{16}\left(\frac{1-\varepsilon}{1+(1-\varepsilon)^{2}}-\frac{1+\ln (1-\varepsilon)}{2(1-\varepsilon)}\right)\left(\frac{1-\varepsilon}{1-\varepsilon_{\max }}\right)^{2} \exp \left(-1.45(1-\varepsilon)\left(1-\varepsilon_{\max }\right)^{0.7}\right) \text {, }
$$

- for determination of permeability along the axis of fibres (along the plane of felting):

$$
K_{2}=0.0043\left(D_{\text {mid }}\right)^{2} /(1-\varepsilon) .
$$

In Fig. 3 the generalizing dependences of liquid permeability coefficient for MFCS with the fibres of $30-\mu \mathrm{m}$ (curves 1 and 2) and $55-\mu \mathrm{m}$ (curves 3 and 4) diameter upon porosity calculated by formula (5) for curves 1 and 3 and by formula (4) for curves 2 and 4 are plotted. The coefficients of MFCS permeability across and along fibres are approximately the same in a wide enough range of porosity up to value $\varepsilon / \varepsilon_{\max } \approx 0.9$. It is explained by homogeneity and regularity of structure in various directions. In the MFCS, the volume porosity of which approaches maximally possible, the structural isotropy is violated and the permeability along the fibres considerably exceeds the latter across them.

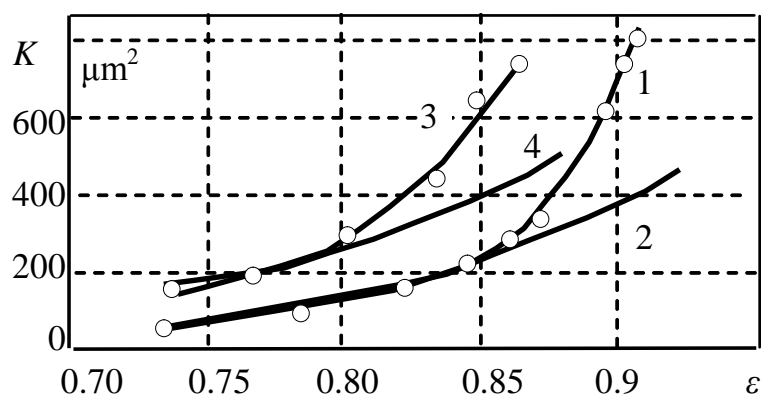

Fig. 3: Dependences of the coefficient of MFCS permeability by liquid upon volume porosity, diameter of fibres, and direction of liquid filtration (curves 1, 2, 3, and 4 - see the text) 
Limiting angle of wetting $\Theta$ of the metals with liquids, as a rule, differs from an ideal angle of wetting that results in diminished values of capillary pressure and, respectively, maximal heat flux transferred by HP. According to the authors' data the values of $\Theta$, measured by the method of lying drop, for the copper-water pair are $72 \pm 2^{\circ}$, for the copper-ethanol pair - 15 $\pm 5^{\circ}$, and for copper with acetone, methanol, methylal, and Freons $-\Theta=0^{\circ}$. However, the method of the capillary rise of liquid in dry MFCS gives other results: copper fibres - acetone $-41 \pm 2^{\circ}$, stainless steel fibres - acetone $-39.5^{\circ}$, copper - ethyl alcohol $-45 \pm 1^{\circ}$, copper ethanol $-40 \pm 1^{\circ}$, and in general water is not absorbed by dry MFCS. Thermal oxidation of CS by the fibres of copper, steel, and nickel sharply improves their wettability by organic heat carriers, practically to $\Theta=0^{\circ}$, and by water - to $8-13^{\circ}$.

The results of the research of available capillary pressure $\Delta P_{\text {cap }}$, coefficients of permeability $K_{1}$ and $K_{2}$ and limiting wetting angles $\Theta$ were approved and confirmed in the study of characteristics of capillary absorption of organic liquids and water by dry MFCS samples made as the plates of $0.5-\mathrm{m}$ by $0.045-\mathrm{m}$ by $0.002-\mathrm{m}$ dimension. Porosity of the samples was within the range from 0.61 to 0.95 , and fibres of $20,30,40$, and $70-\mu \mathrm{m}$ diameter of copper and stainless steel were used. The research performed has shown a high capillary-transport ability of MFCS not only at horizontal orientation, but also at operation against gravity. Rate of MFCS saturation with working fluids was found to be much higher than that of CS made of screens and fabrics.

\section{HEAT CONDUCTIVITY OF MFCS}

Experimental data on heat conductivity of MFCS available in the references differ considerably from the results of the calculations by the theoretical and semi-empiric formulas of the heat conductivity of porous bodies. It is explained mainly by neglecting thermal resistance of heat conductivity of contacts between dispersible discrete elements forming a porous structure. Technology of MFCS fabrication, including the processes of pressing and sintering, provides a good thermal contact between separate fibres. However, as follows from the results of metallographic analysis, the contact is not perfect. Equivalent diameter of spot of the contact between the sintered fibres is less than fibre diameter, i.e., the ratio of these two magnitudes $(y)$, as a rule, is within $0<y \leq 1$. The value of $y$ formed due to the processes of sintering $\left(y_{1}\right)$ and pressing $\left(y_{2}\right)$, can be calculated by the dependences based on experimental data processing:

$$
y=y_{1}+y_{2}, ; \quad y_{1}=c \varepsilon^{0.1}\left(l_{f} / d_{f}\right)^{0.5}, 0<y_{1}<1 ; \quad y_{2}=(1+c) d_{f}^{-0,13}-\varepsilon, \quad 0 \leq y_{2}<1 \text {, }
$$

where $d_{f}$ and $l_{f}$ are in micrometers, while coefficient $c$ depends on the material of fibres and technological parameters. This equals 0.031 for copper, 0.05 for stainless steel, 0.065 for nickel, and 0.08 for nichrome.

For calculation of the effective heat conductivity of the porous materials made of discrete fibres across a plane of felting the authors offer the following analytical dependence:

$$
\lambda_{\text {eff }}=\lambda_{1}\left[(1-\varepsilon)^{2} M+\varepsilon^{2} \beta+\frac{4 \beta \varepsilon(1-\varepsilon)}{1+\beta}\right],
$$

where $\beta=\lambda_{s} / \lambda_{1} ; \lambda_{s}, \lambda_{1}$ are the coefficients of heat conductivity of fibre material and liquid.

Parameter $M$ reflects the influence of imperfection of contacts between fibres upon heat transfer in the contact area: 


$$
\begin{aligned}
& M=y+\left[2 A \sqrt{1-y^{2}}(1-y)\right] /\left[A \sqrt{1-y^{2}}+(1-y)\right] \\
& A=\sqrt{\pi} \beta(1-\beta)\left((1-\beta)^{-1} \ln \beta^{-1}-1\right) .
\end{aligned}
$$

The same formulas can be used for the calculation of frame heat conductivity of MFCS $\left(\lambda_{s}=\right.$ 0 and $\left.\beta=\lambda_{s} / \lambda_{1}=0\right)$.

Fig. 4 reflects the experimental data both of the authors and of other researchers and plots the curves, calculated by formulas (7) and (8) for effective heat conductivity of the MFCS from stainless steel (curve I), nickel (curve II), and copper (curves III to VIII), made of fibres of 30- $\mu \mathrm{m}$ and 3-mm (curve I), 50- $\mu \mathrm{m}$ and 3-mm (curve II), 70- $\mu \mathrm{m}$ and 3-mm (curve III), 40$\mu \mathrm{m}$ and 3-mm (curve IV), 70- $\mu \mathrm{m}$ and 10-mm (curve V), 20- $\mu \mathrm{m}$ and 3-mm (curve VI), 40- $\mu \mathrm{m}$ and 10-mm (curve VII), 20- $\mu \mathrm{m}$ and 10-mm (curve VIII) diameters and lengths, respectively.

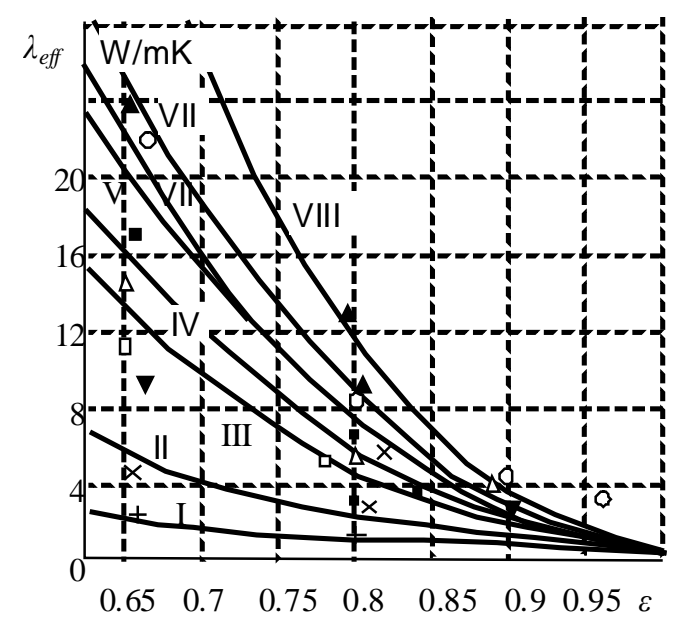

Fig. 4. Coefficients of effective heat conductivity of MFCS saturated with water versus porosity

Increase in CS porosity, shortening of discrete fibres, and increase in their diameter reduce both effective and frame heat conductivity of MFCS. Substantial distinction between experimental and calculated data is observed only for CS with porosity close to the highest possible, where the structure becomes non-isotropic.

\section{STUDY OF MFCS MECHANICAL PROPERTIES}

Except for structural, hydrodynamic, thermophysical characteristics of MFCS and their capillary-transport properties, in a number of cases, knowledge of mechanical properties of porous structures is needed, for example, for the structures used in full-scale solar receivers with sodium as the heat carrier.

The authors investigated mechanical properties of CS with the porosity from 0.8 to 0.99 and the thickness from 2 to $5 \mathrm{~mm}$ of stainless-steel discrete fibres with the diameter from 4 to 55 $\mu \mathrm{m}$ and the length of 3 and $10 \mathrm{~mm}$. The fibres were sintered with each other and with substrates or dome of the receiver made of Haynes Alloy 230. Research was conducted at the temperature of 20 and $750{ }^{\circ} \mathrm{C}$ on the test benches, described in (Baturkin et al., 2002, 2005). 
Dependences of some mechanical properties of MFCS upon their porosity $\varepsilon$ (a) and relative porosity $\varepsilon / \varepsilon_{\max }$ (b) are shown in Fig. 5 . The values of proportional limit of MFCS at elongation are substantially reduced not only with an increase in their porosity and decrease in fibre diameter, but also with a rise in temperature of operation (approximately 5-fold reduction).
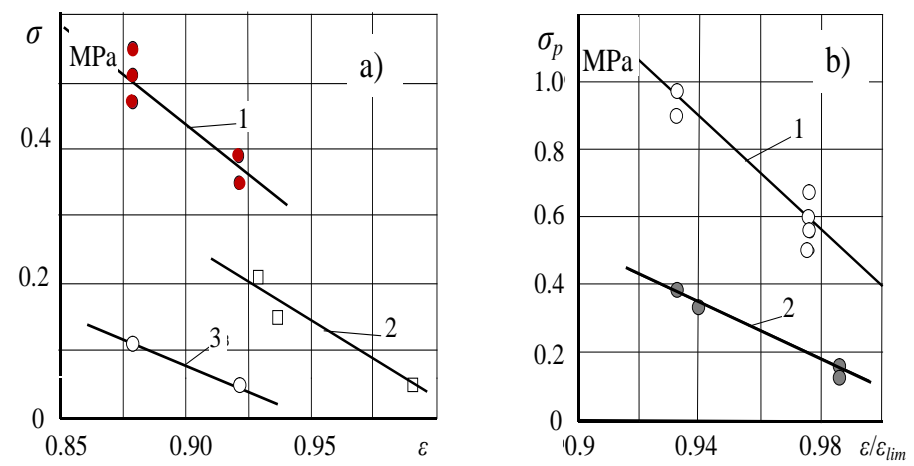

Fig. 5. Proportional limits at elongation of MFCS (a) and pullout forces from substrate (b) versus porosity. Lines 1 and 3: fibre of 30- $\mu \mathrm{m}$ diameter and 3-mm length; line 2: 8- $\mu \mathrm{m}$ and 10-mm, respectively. Temperature of tests: lines 1 and 2: $20{ }^{\circ} \mathrm{C}$; line $3: 750{ }^{\circ} \mathrm{C}$.

The proportional limits at the compression of MFCS under the conditions of high temperature $\left(750{ }^{\circ} \mathrm{C}\right)$ have similar dependences and for the structures from fibres of $8-\mu \mathrm{m}$ diameter equal: 2 to $3 \mathrm{kPa}$ (porosity 0.993 ) and 5 to $7 \mathrm{kPa}(0.985)$, from $30-\mu \mathrm{m}$ fibres -13 to $15 \mathrm{kPa}(0.9)$ and 15 to $18 \mathrm{kPa}(0.85)$, from $55-\mu \mathrm{m}$ fibres -19 to $20 \mathrm{kPa}(0.85)$ and 22 to 23 $\mathrm{kPa}(0.82)$.

The study confirmed possibility of application of MFCS even in high-temperature heat pipes of large sizes. However, not all CS designs were suitable for this application. So, the structures from ultra-fine fibres (of 4 and $8-\mu \mathrm{m}$ diameter) do not possess sufficient mechanical properties required at the temperature of $800{ }^{\circ} \mathrm{C}$ in full-scale high-temperature solar receivers.

\section{APPLICATION OF HEAT PIPES WITH MFCS}

The field of application of MFCS in HP is determined by the following features. Technology of fabrication of capillary structures allows CS with the specified structural parameters, which can be repeatedly reproduced, to realize the reliable fastening and contact of CS with the HP case, to fit CS to the surface of complex shape, and to put HP with CS into proper shape.

Hydrodynamic, capillary-transport and thermophysical characteristics and properties of MFCS can be expressed by clear enough functions of initial structural parameters.

The above-mentioned advantages are the necessary terms of receipt of reliable functional correlations between the structural parameters of CS and heat-and-mass transfer characteristics of HP, which do not vary during HP operation and could be calculated and optimized.

As compared with other types of inserted CS, high capillary-transport properties of MFCS under the conditions of availability or lack of counteractive impact of mass forces are 
explained by the specifics of MFCS structure consisting in high limiting porosity, absence of the closed and one-side open pores, and low convolution of pore channels.

Heat pipes with MFCS possess high heat-transfer ability and low thermal resistance either in presence or absence of counteractive impact of mass forces. On the basis of such CS a number of HP modifications are created, such as gas-regulated heat pipes, thermal diodes, thermal siphons, and loop heat pipes.

\section{CONCLUSIONS}

The conducted study of structural, hydrodynamic, thermophysical and mechanical properties of metal-felt capillary structures have shown expediency of their application as the wicks of heat pipes. The technology gives the possibility to make HP of any form, to create complex capillary structures with reliable hydraulic and mechanical connection, to attain reiteration of the designed CS properties, and to deform the HP case without wick damage or performance degradation when mounting.

The aforesaid is confirmed by long experience of application of HP with MFCS in such fields, as cooling, temperature control of various electronics, cooling of the aircraft devices, including space vehicles, provision of proper thermal conditions of optical, analytical and precision instruments, e.g., lasers, cooling of mechanical and electrotechnical equipment, technological treatment of materials, medical engineering, etc.

\section{REFERENCES}

Adkins, D.R., Moss, T.A., Andraka, C.E., Andreas, N.H. and Cole, H.M., (1995) An Examination of Metal Felt Wicks for Heat-Pipe Applications, Proc. of ASME and JSME Japan Solar Energy Society Intl. Solar Energy Conf., March 19-24, Maui, HI.

Baturkin, V., Zaripov, V., Kravetz, V., Nishchik, A. and Moreno, A., (2002) Research of Structural and Mechanical Properties of Metal Fiber Capillary Structures Intended for HighTemperature Heat-Pipes Solar Absorbers, J. Energetika, Economika, Technologia, Ecologia, Kyiv: 2, pp. 41-46 (in Russian).

Baturkin,V., Zaripov,V. and Andraka, C., (2005) Technological Peculiarities and Calculation of Capillary Structure Parameters for Heat-Pipe Absorbers of Solar Power Plants, J. Energetika, Economika, Technologia, Ecologia. Kyiv: 2, pp. 27-34 (in Russian).

Kostornov, A.G., (2002) Materials Science of Dispersed and Porous Metals and Alloys, Kyiv: Naukova dumka, (in two volumes) vol. 1, 568 pages (in Russian).

Semena, M.G., Gershuni, A.N. and Zaripov, V.K., (1984) Heat pipes with metal fiber capillary structures, Kyiv: Vyshcha shkola, 215 pages (in Russian). 